\title{
The extent of sigmoidoscopy shown on radiographs with special reference to the rectosigmoid junction
}

\author{
M. R. MADIGAN AND J. M. HALLS \\ From St. Mark's Hospital, London
}

The purpose of this investigation is to show what parts of the rectum and pelvic colon are seen on sigmoidoscopy, the reason for the occasional inability to pass the instrument to its full length, and the areas where special care is necessary in looking for lesions.

\section{METHOD}

Patients referred for routine barium enema examination from St. Mark's Hospital Out-Patient Department were selected for this study. The very young, the aged and infirm, women of childbearing age, and those with painful local lesions were excluded. Sixty-two patients were examined.

The double-constrast enema technique (Young, 1966), was used for the radiological investigation of the colon and at the end of this examination a $25 \times 1.3 \mathrm{~cm}$ or $30 \times 1.9 \mathrm{~cm}$ Lloyd-Davies type of sigmoidoscope was inserted. An occasional difficulty was due to pooling of residual liquid barium suspension in the rectum. Elaborate attempts were not made to clear the bowel of barium and if after several attempts the sigmoidoscope could not be passed to its full length it was strapped to the buttocks with adhesive tape. The length of tube inserted was carefully read at the anal margin. If fulllength insertion was achieved the sigmoidoscope was similarly taped to the buttocks. Two films were then made, one with the patient supine, and one with the patient in the left lateral position, using an overcouch tube with a focus-film distance of $48 \mathrm{in}$. The instrument was then removed.

In some cases a Michel clip was attached to the mucosa using a long forceps, and the sigmoidoscope was then withdrawn before the films were taken. This allows for safer movement of the patient.

Figure 1 is the double-contrast radiograph of the rectosigmoid region. Figure 2 shows the sigmoidoscope inserted to $25 \mathrm{~cm}$. Figure 3 shows a Michel clip attached to the mucosa after withdrawal of the sigmoidoscope.

A plaster of Paris cast of a fist was made, with extended index finger, which measured $8.5 \mathrm{~cm}$ from tip to web, with a partial lead covering to increase density. By means of a wooden rod fixed in the base a digital rectal

${ }^{1}$ Present address: St. Michael's Hospital, Toronto 2, Canada examination was simulated, while postero-anterior and left lateral exposures were made as before.

Figures 4 and 5 show the limits of digital examination.

The technique and dangers of sigmoidoscopy are covered adequately in most standard works on the rectum and colon. A reminder of the anatomy of the rectum will assist in interpretating the radiographs.

\section{ANATOMY}

RECTUM The rectum ends distally by becoming continuous with the anal canal, which site is readily recognized by palpation of the ano-rectal ring, the ridge of pubo-rectalis muscle felt where the anorectal junction is angulated forward as it passes through the levator diaphragm. This point is about $3 \mathrm{~cm}$ from the anal margin. The rectum is about $12 \mathrm{~cm}$ long, following the curve of the sacrum. From above downward it also has three lateral bends, to the right, left, and right again, recognizable from the lumen as folds of the rectal wall, the valves of Houston. These are more constantly seen radiologically than sigmoidoscopically. The site where the rectum begins and the colon ends is known as the rectosigmoid junction.

RECTOSIGMOID JUNCTION There is no constant embryological, anatomical, pathological, or histological feature to distinguish this point (unlike the ano-rectal junction), which explains the many definitions, all of which are arbitrary. These include consideration of the configuration of the pelvic mesocolon and peritoneum, the alterations of the outer longitudinal muscle layer from the three taenia coli to an enveloping layer, the point of division of the superior haemorrhoidal artery, the rugosity of the pelvic colonic mucosa, and the slight narrowing of the lumen of the pelvic colon. A frequently quoted definition is that part of the bowel opposite the third sacral vertebra.

If at laparotomy the sigmoid colon is withdrawn from the pelvis and the rectum straightened, then 


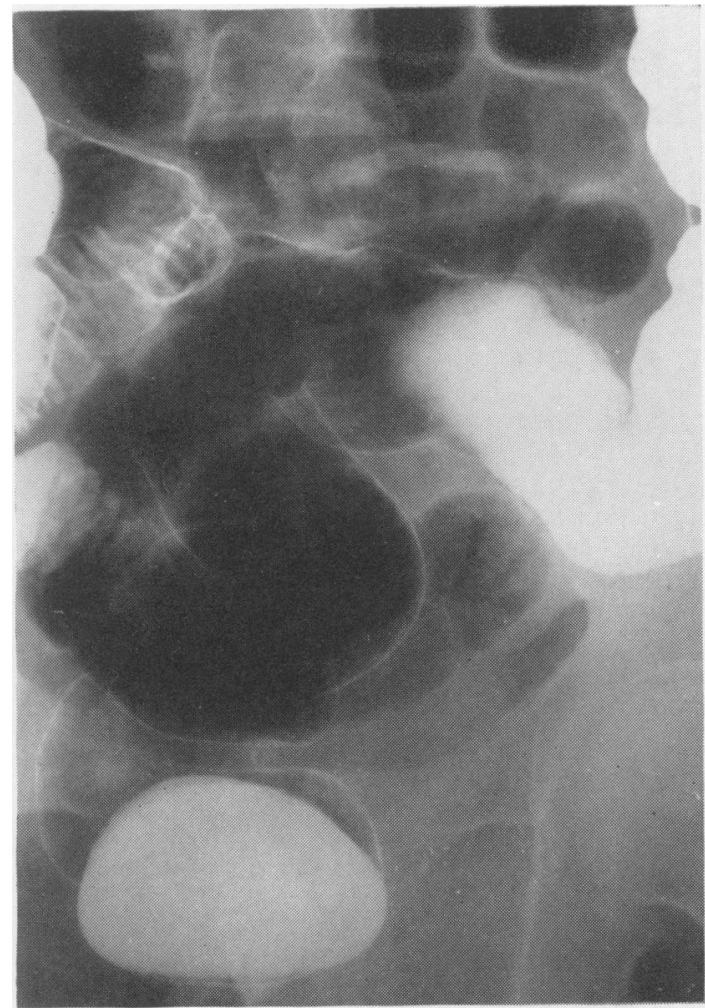

FIG. 1.

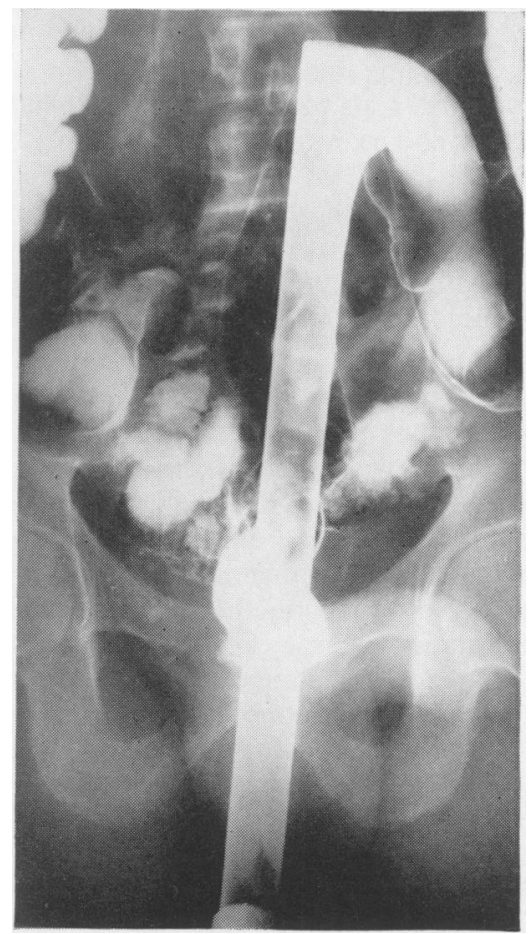

FIG. 2.

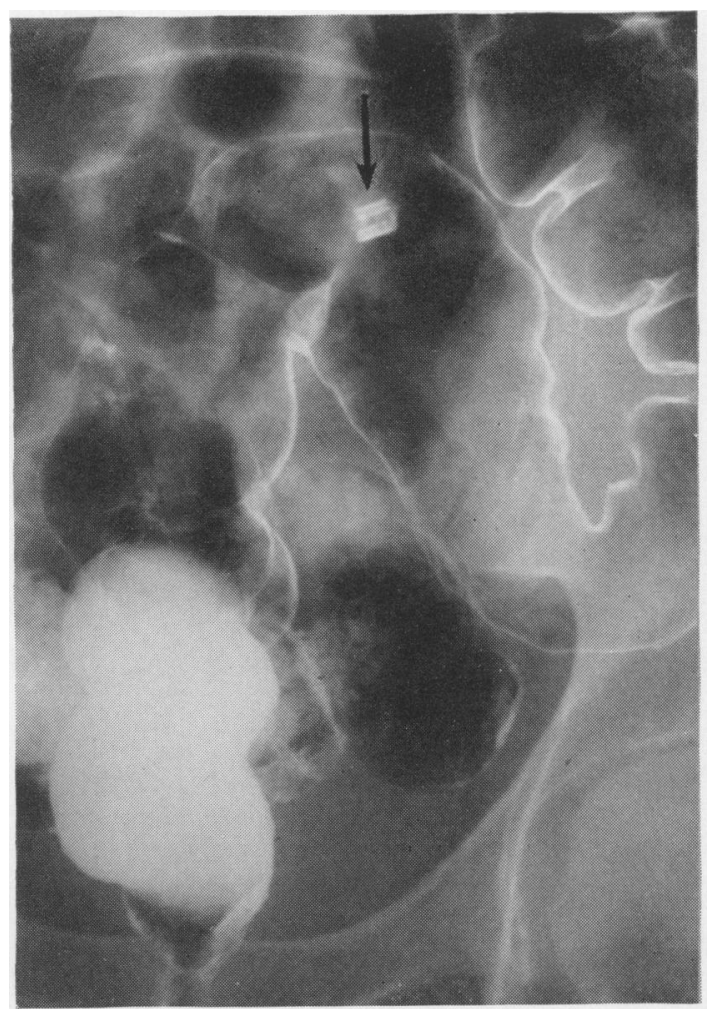

FIG. 3.

FIG. 1. Double-contrast enema of rectosigmoid area.

FIG. 2. Same case as in Figure 1. Sigmoidoscope inserted to $25 \mathrm{~cm}$.

FIG. 3. Same case as in Figure 1. Michel clip at $25 \mathrm{~cm}$.

$\stackrel{\Omega}{\risingdotseq}$ 


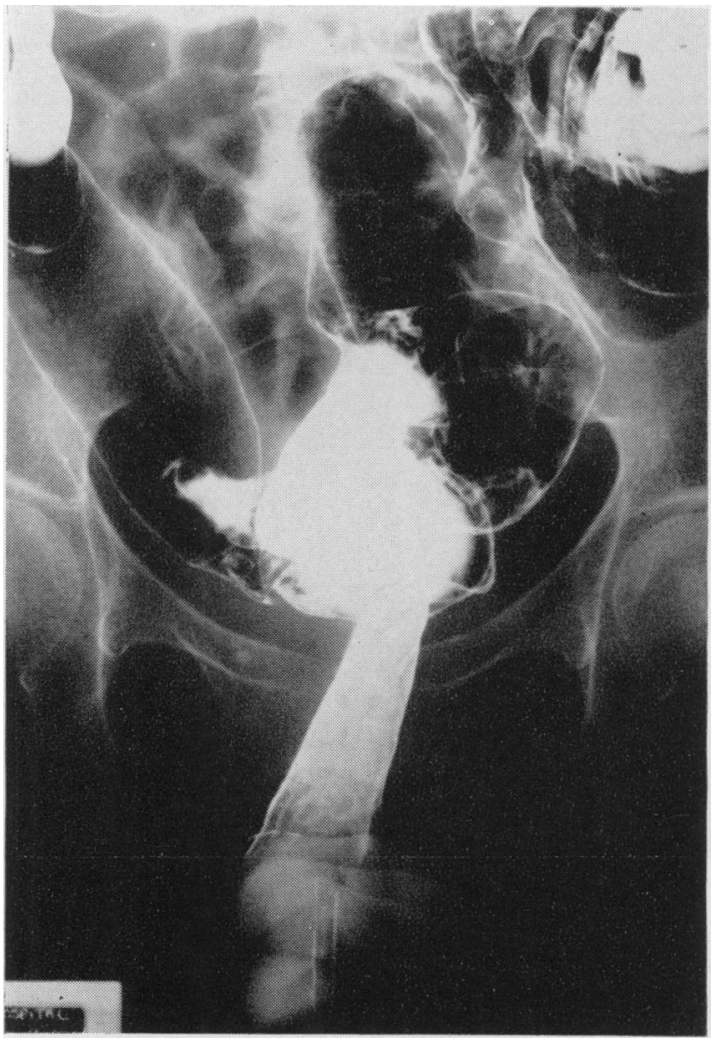

FIG. 4.

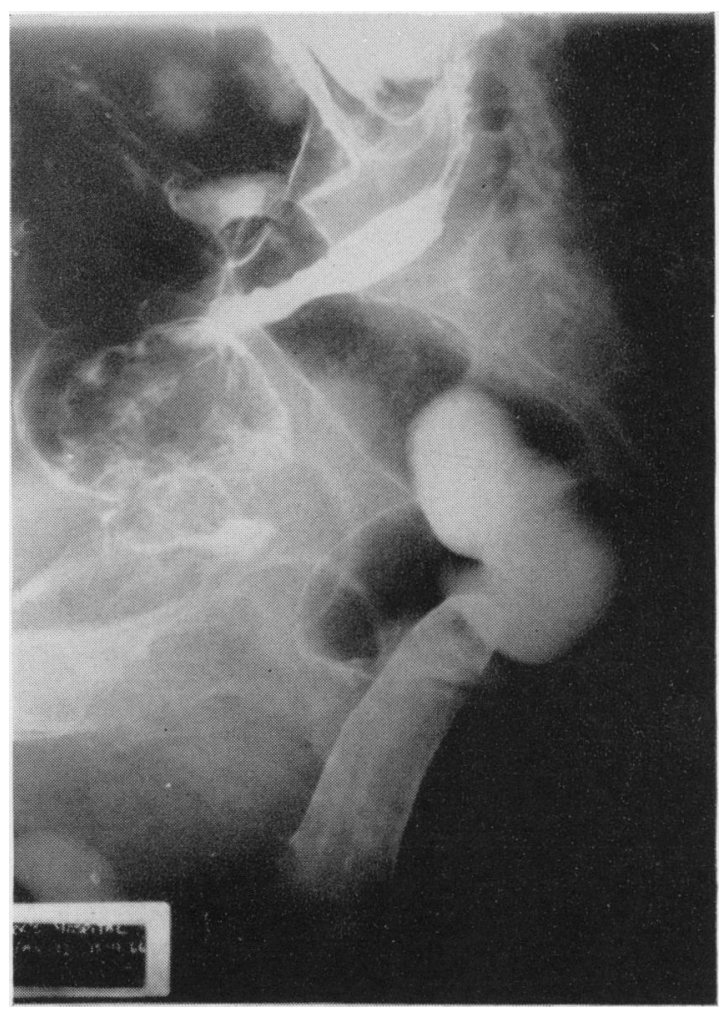

FIG. 5 .

FIG. 4. Simulated digital examination. Postero-anterior film.

FIG. 5. Same case as in Figure 4. Lateral film.

at a point just below the sacral promontory several of the above conditions obtain, viz., the taenia coli have fused, the mesocolon is no longer leaf-like, and the sigmoid branches have left the trunk of the inferior mesenteric artery which now becomes the single superior rectal (haemorrhoidal) artery. There is a larger subperitoneal and a smaller supraperitoneal part of the rectum. This is the best surgical definition of the rectosigmoid junction, which point is about $15 \mathrm{~cm}$ from the anal verge. But it cannot be determined accurately from below. Therefore on sigmoidoscopy when a precise location is necessary for comparing lesions, or considering the location of instruments inserted for measuring bowel function, the distance from the anal margin should be stated, since 'rectosigmoid junction' refers to an ill-defined area under these conditions.

PELVIC (SIGMOID) COLON This is also arbitrarily defined as that part of the colon between the descending colon and rectum. It has a mesentery.
The beginning is defined as being opposite the margin of the left psoas major muscle or the left iliac crest. It varies greatly in length.

\section{OBSERVATIONS}

Hughes (1957) states that $25 \%$ of sigmoidoscopies fail to go to the full length of $25 \mathrm{~cm}$ while Jackman (1958) quotes $14.8 \%$ of failures in 19,294 examinations at the Mayo Clinic in 1955. Full insertion failed in $58 \%$ of our cases, which represents a partially selected group since many were referred for barium enema examinations for this very reason.

Sigmoidoscopy may be limited by those lesions which block or narrow the bowel lumen, fix it abnormally to the surrounding structures, or by gross skeletal deformity. In the majority of cases we found that failure to pass the rigid metal tube for a distance of $25 \mathrm{~cm}$ or more was due to an acute flexure, usually in the region of the rectosigmoid area. This sharp bend is produced by the 


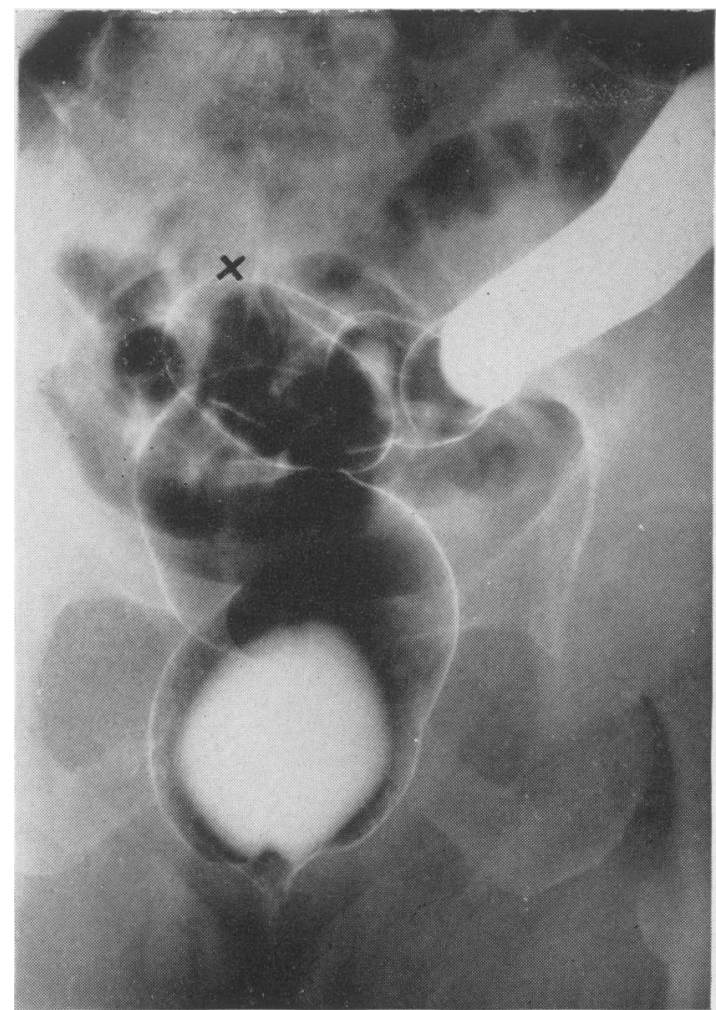

FIG. 6 .

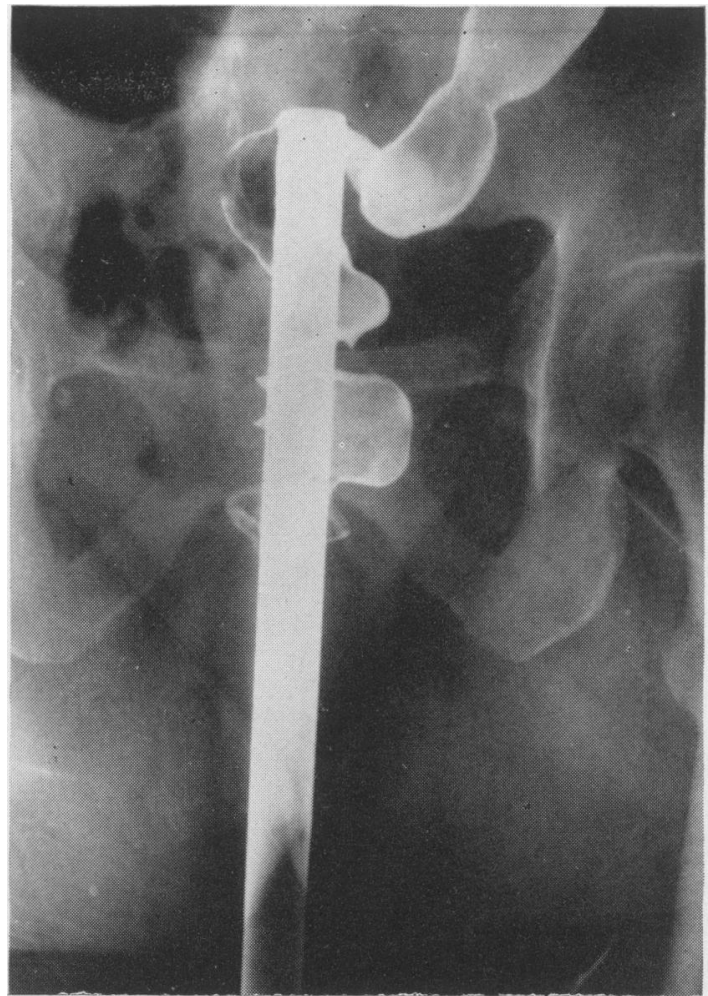

FIG. 7.

FIG. 6. Double-contrast enema showing acute flexure.

FIG. 7. Same case as in Figure 6. Sigmoidoscope would not pass beyond $16 \mathrm{~cm}$. Antero-posterior film.

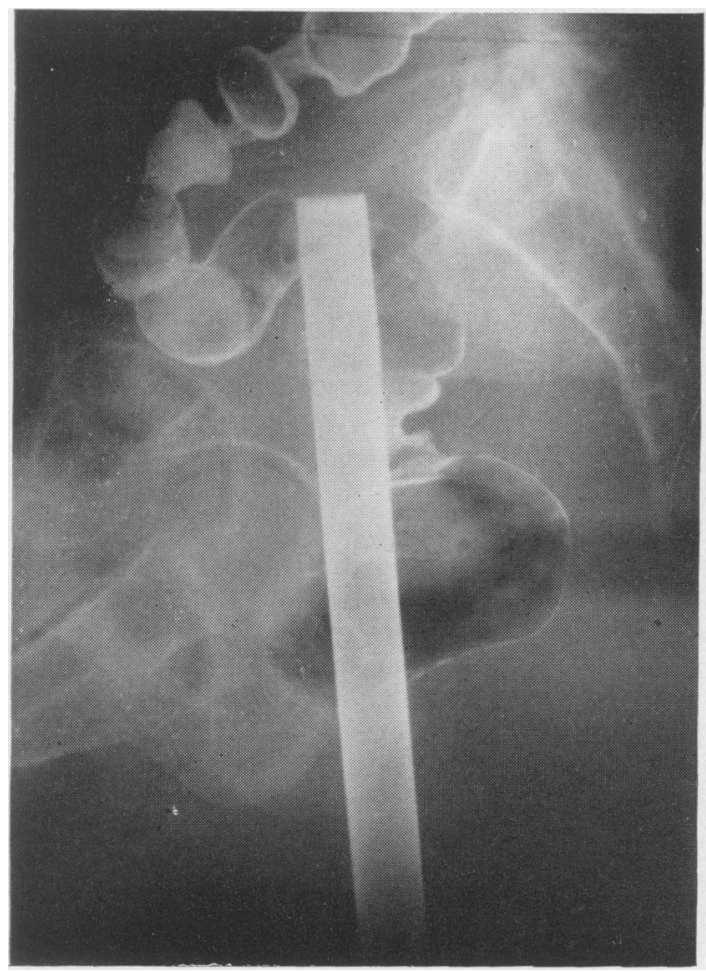

FIG. 8.

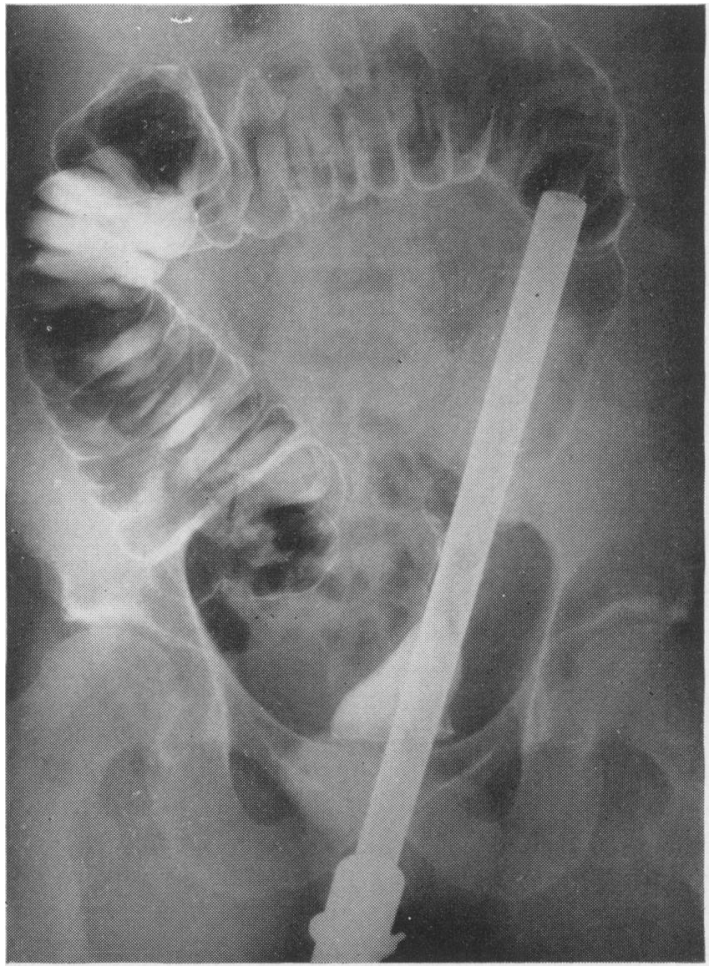

FIG. 9.

FIG. 8. Same case as in Figure 6. Lateral view.

FIG. 9. Easy full insertion of sigmoidoscope to $30 \mathrm{~cm}$ after resection of pelvic colon. 


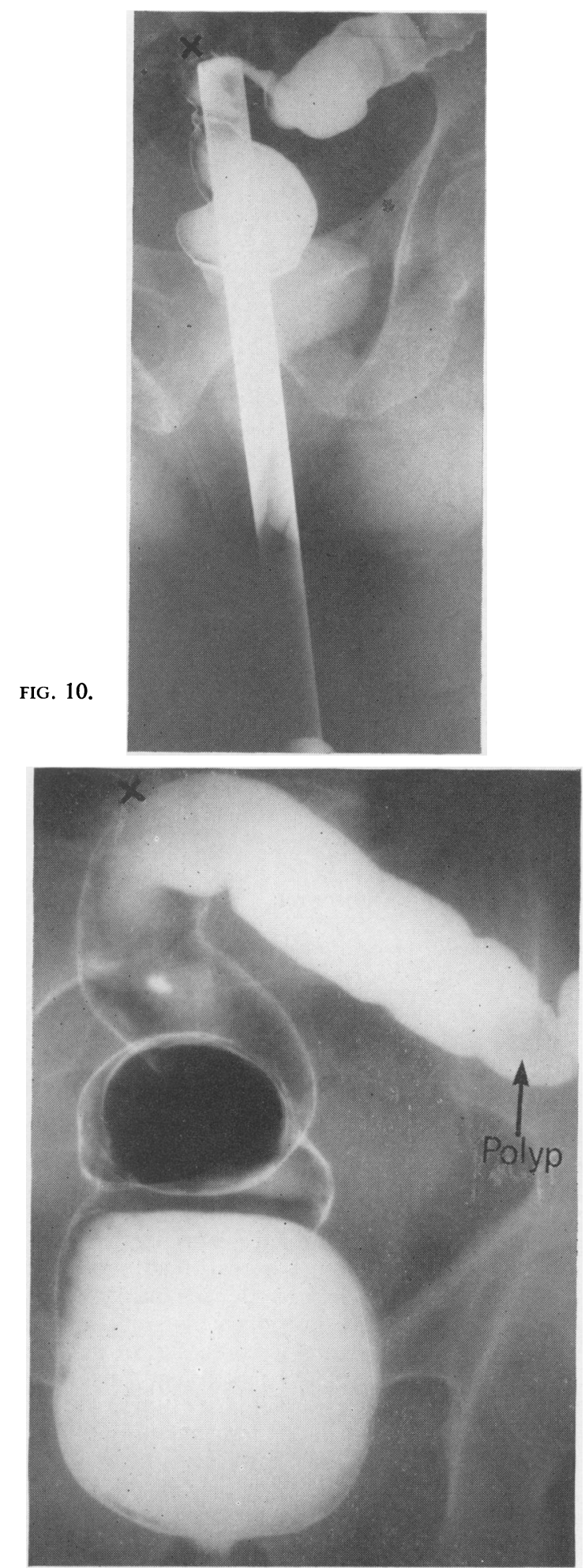

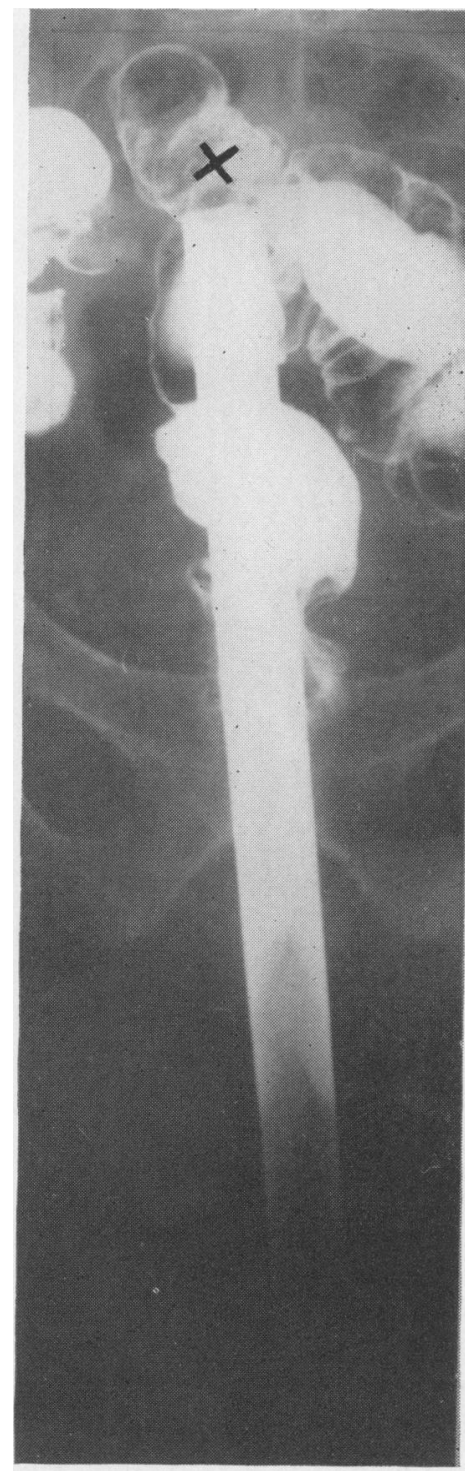

FIG. 11.

FIG. 10. Patient examined in left lateral position. Sigmoidoscope held up by acute flexture at $13 \mathrm{~cm}$.

FIG. 11. Same case as in Figure 10, with patient examined in knee-chest position. A loop of terminal ileum has appeared behind the flexure in this position, partially obscuring it. Insertion held up at $13 \mathrm{~cm}$ as before.

FIG. 12. Double-contrast enema showing a polyp in the sigmoid colon. 


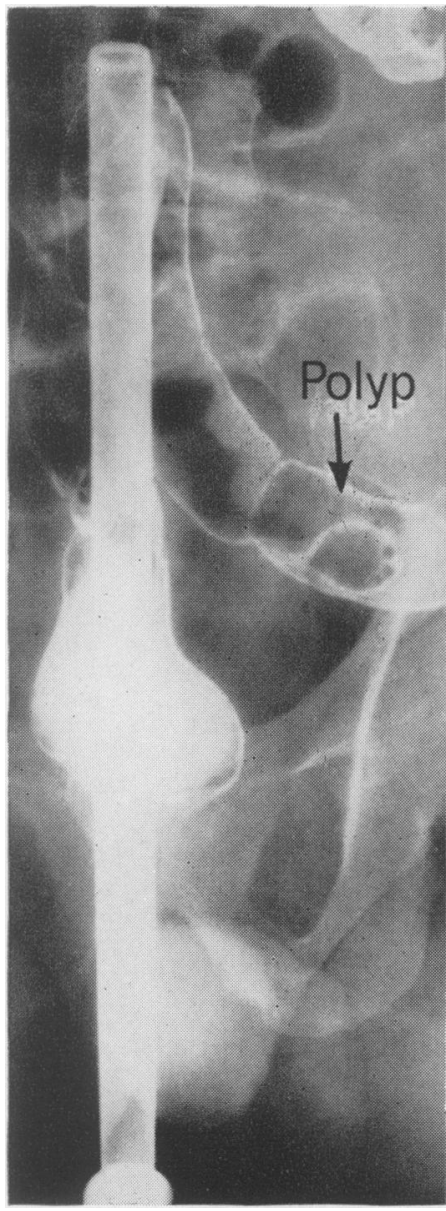

FIG. 13.

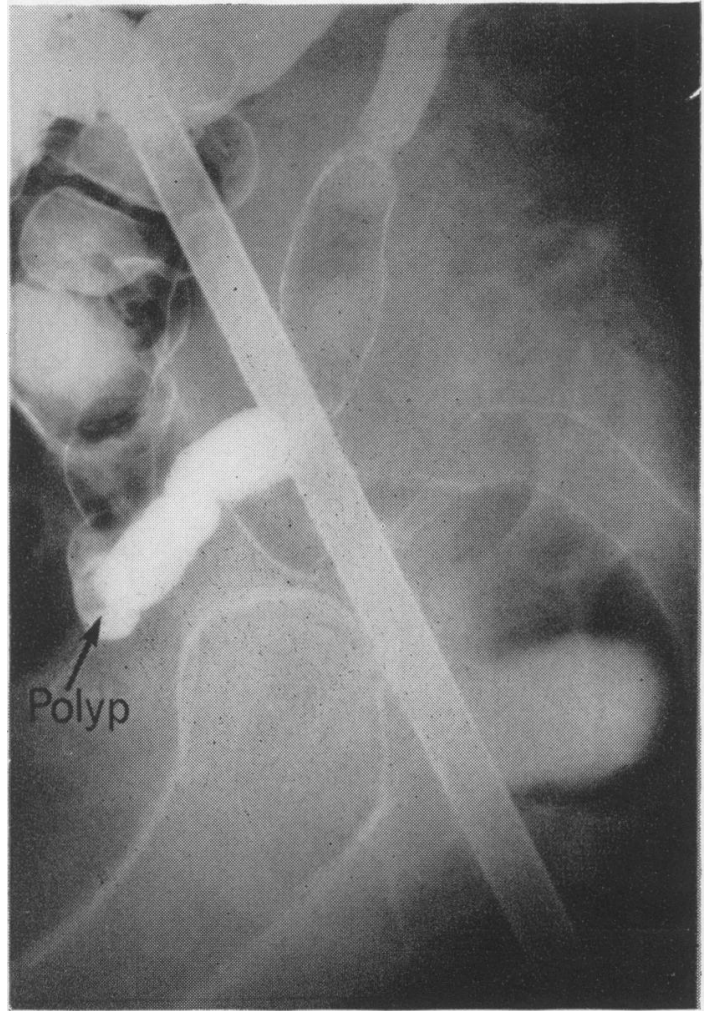

FIG. 14.

FIG. 13. Same case as in Figure 12. Sigmoidoscopy to $25 \mathrm{~cm}$, showing polyp out of range of the instrument.

FIG. 14. Same case as in Figure 12. Lateral view. sweep of the sigmoid colon as it runs forwards away from the rectum and its angle is greater than $90^{\circ}$ and often approaches $180^{\circ}$. The distance of this flexure from the anal margin varies from patient to patient. Even in those with a flexure below $25 \mathrm{~cm}$ full insertion may be possible because of stretching of the rectum. The average distance from the anal margin in this series was $17.5 \mathrm{~cm}$ with a range from 12 to $24 \mathrm{~cm}$. Figures 6,7 , and 8 demonstrate the impassable acute flexure.

In those patients who have had this flexure removed by resection of the pelvic colon the instrument can be readily passed to the full distance (Fig. 9).

The acute flexure is relatively constant, for the angle does not straighten out on manoeuvring the patient even though the position of the rectosigmoid area may change in relation to other organs (Figs. 10 and 11$)$.
Hence the knee-chest or other positions of the patient do not improve the chances of full insertion since the sigmoid colon will bear a similar relationship to the rectum in whatever position the patient is examined. This point can be demonstrated at operation when the abdomen is open. If the sigmoidoscope is passed from the anus in the usual way, and there is an acute rectosigmoid angle, the abdominal operator has to thread the stretched sigmoid colon over the instrument by straightening out the kinks, rather than just altering the relative position of the rectum and pelvic colon. There may be other merits for these different postures, such as an easier introduction of the instrument or greater convenience to patient and operator.

General anaesthesia will not help in passing the sigmoidoscope beyond the acute bend for the same reason. It may be required for other reasons, such as an extremely nervous patient, or a painful lesion 


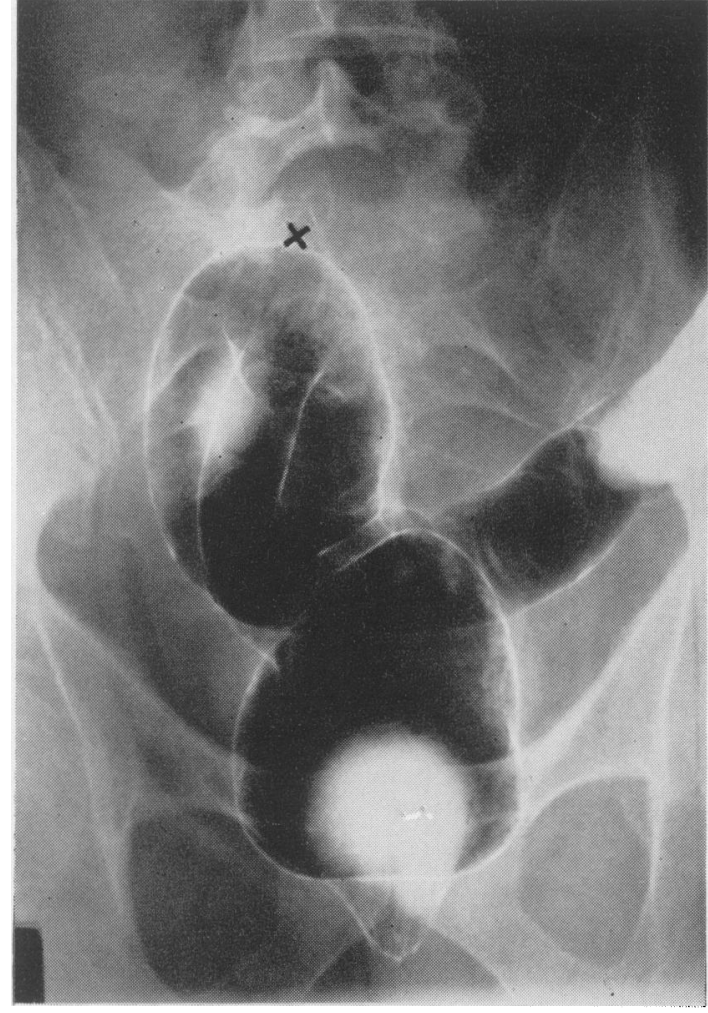

FIG. 15 .

FIG. 15. Acute flexure at the rectosigmoid area.

FIG. 16. Same case as in Figure 15. Full instrumentation achieved by stretching the rectum. accompanied by spasm of the sphincters as in anal fissure, thus allowing dorsal displacement of the anus.

The unnegotiable acute flexure can be recognized on the barium enema films. We soon found that we could predict the site and roughly the distance from the anal margin of the bend above which a lesion is not available for viewing, or biopsy, with the sigmoidoscope. Figure 12 shows in the contrast film a polyp in the sigmoid colon beyond an acute rectosigmoid flexure judged out of range of the sigmoidoscope. Figures 13 and 14 confirmed this opinion.

Stretching of the rectum may give the false impression that the tip of the instrument lies within the colon because it has passed $20-25 \mathrm{~cm}$, when in fact it has only reached the rectosigmoid region or last few centimetres of sigmoid colon (Figs. 15 and 16). This explains how a polyp seen at $20 \mathrm{~cm}$ or more may sometimes be prolapsed easily through the anus for tying the pedicle.

Figures 14 and 16 illustrate how the use of direct force or a turning moment could push the instrument

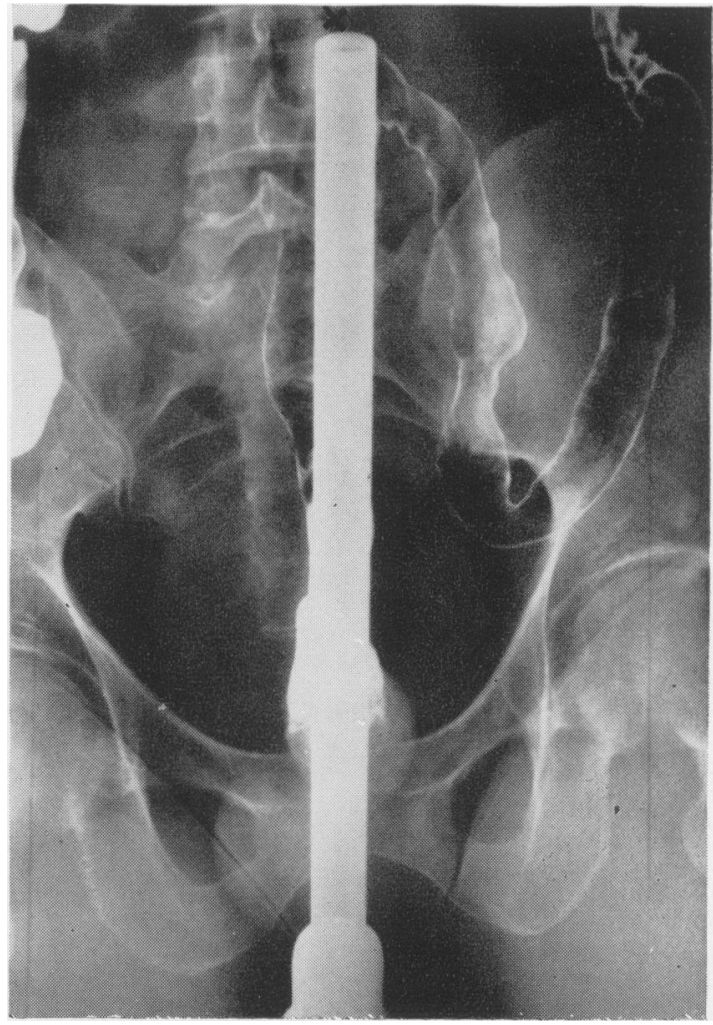

FIG. 16. through the bowel or split the wall where it stretches over a fixed point such as the sacral promontary. The patient's reaction to pain is a valuable check in preventing injury, a further reason for avoiding general anaesthesia if possible.

The relationship of the examining finger to the bony pelvis is shown in Figures 4 and 5. The distance reached can be up to $10 \mathrm{~cm}$ and depends on the length of the finger and how vigorously the perineum is invaginated by the fist. This is very difficult in the obese, when it may only be possible to reach the distal rectum at 3 to $4 \mathrm{~cm}$.

Metal clips held in long forceps are easily attached to the mucosa seen at the end of the sigmoidoscope (Spencer, Jackman, and Witten, 1962). Films taken after the instrument has been withdrawn will show the furthest point reached, although it is then sometimes difficult to identify the folds of bowel which have been traversed (Fig. 3).

\section{CONCLUSIONS}

The acute flexure in the rectosigmoid area is usually 
the limiting factor preventing full instrumentation with a sigmoidoscope.

Altering the position of the patient or general anaesthesia does not help in negotiating an acute flexure impassable in the original position.

False readings of full insertion can be obtained by stretching of the rectum, when an impassable flexure is less than $25 \mathrm{~cm}$ from the anal margin.

It is possible to predict from radiographs whether a lesion is within reach of the sigmoidoscope.

A double-contrast enema is necesssary for investigation of those areas proximal to an impassable flexure.

\section{REFERENCES}

Hughes, E. S. R. (1957). Surgery of the Anus, Anal Canal and Rectum. Livingstone, Edinburgh and London.

Jackman, R. J. (1958). Lesions of the Lower Bowel. Thomas, Springfield, Illinois.

Spencer, R. J., Jackman, R. J., and Witten, D. M. (1962). New device for delineating polyps of the lower bowel. Proc. Mayo Clin. 37, $451-453$.

Young, A. C. (1966). In Modern Trends in Surgery, edited by W. T. Irvine. Butterworths, London.

\section{The April 1968 Issue \\ THE APRIL 1968 ISSUE CONTAINS THE FOLLOWING PAPERS}

Signposts

Pepsinogens and pepsins MICHAEL D. TURNER

Effect of irritant purgatives on the myenteric plexus in man and the mouse BARBARA SMITH

Prognostic value of the serum proteins during severe attacks of ulcerative colitis F. T. DE DOMBAL

Radiological signs of ulcerative colitis: assessment of their reliability by means of observer variation studies N. GEFFEN, A DARNBorough, F. T. DE DOMBal, G. WATKINSON, and J. C. GOLIGHER

Radiological appearances of ulcerative colitis: an evaluation of their clinical significance F. T. DE DOMBAL, N. GEFFEN, A. DARNBOROUGH, G. WATKINSON, and J. C. GOLIGHER

Crohn's disease of the colon v. J. MCGOVERN and S. J. M. GOULSTON

Effect of different foods on the acidity of the gastric contents in patients with duodenal ulcer. Part III: Effect of altering the proportions of protein and carbohydrate J. E. LENNARD-JONES, JANET FLETCHER, and D. G. SHAW

Effect of diet on faecal and urine urobilonogen excretion and its possible relationship to the pathogenesis of peptic ulceration S. L. MALHOTRA

Partial biliary obstruction with cholangitis producing a blind loop syndrome A. J. SCOTT and G. A. KHAN

Immunoglobulins in chronic liver disease TEN FEIZI
Reproducibility of the heaptic uptake test of vitamin $B_{12}$ absorption J. D. TOWNSEND, T. SMITH, and M. J. S. LANGMAN

Action of metoclopramide on gastric emptying and small bowel transit time W. B. JAMES and R. HUME

Electrical activity across human foetal small intestine associated with absorption processes R. J. LEVIN, $O$. KOLDOVSKÝ, J. HOŠKovÁ, V. JIRSOVÁ, and J. UHER

Cephalic phase of pancreatic secretion in man $\mathrm{H}$. SARLES, R. DANI, G. PREZELIN, C. SOUVILLE, and C. FIGARELLA

Carcinoma of the duodenum LOUIS KREEL and COLIN MACKINTOSH

Candida infection of the oesophagus JOHN M. HOLT

Computer analysis of intraluminal pressure records

J. J. MiSIEWICZ, SHEILA L. WALlER, M. J. R. HEAly, and E. A. PIPER

New clinical method for measuring the rate of gastric emptying: the double sampling test meal J. D. GEORGE

A new method of objective examination in proctology RAYMOND P. J. KERREMANS

Device for obtaining samples of intestinal contents for microbiological and biochemical examinations I. SKÅLA and J. ŠIMÁČEK

Gastroenterological Society of Australia

European Pancreatic Club

Notes and activities

Copies are still available and may be obtained from the PUBLISHING MANAGER, BRITISH MEDICAL ASSOCIATION, TAVISTOCK SQUARE, W.C.1, price 18s. 6D. 